\title{
miRNA-24 Down-Regulates Endothelial Nitric Oxide Synthase Expression and Inhibits Endothelial Cell Tube Formation
}

\section{Xuelan Luo}

Guangxi International Zhuang Medicine Hospital Affiliated to Guangxi University of Chinese Medicine

\section{Wei Chen}

Jinan Maternity and Child Care Hospital

\section{Yuwang Qin}

Guangxi International Zhuang Medicine Hospital Affiliated to Guangxi University of Chinese Medicine

\section{$\mathrm{Na}$ Gan}

Guangxi International Zhuang Medicine Hospital Affiliated to Guangxi National University of Traditional Chinese Medicine

\section{Dongning Lvy}

GuangXi University of Chinese Medicine

\section{Zhenguo Liu}

University of Missouri-Columbia School of Medicine

\section{Hesheng Ou ( 2676611767@qq.com)}

Guangxi International Zhuang Medicine Hospital Affiliated to Guangxi National University of Traditional Chinese Medicine https://orcid.org/0000-0001-9708-8384

\section{Research article}

Keywords: MicroRNA (miRNA or miR)-24, Human umbilical vein endothelial cells (HUVECs), Tube formation, Endothelial nitric oxide synthase (eNOS), Sp1

Posted Date: August 25th, 2020

DOl: https://doi.org/10.21203/rs.3.rs-63873/v1

License: (c) (1) This work is licensed under a Creative Commons Attribution 4.0 International License. Read Full License 


\section{Abstract}

Background: This study is to investigate the effects of miR-24 on expression of eNOS and Sp1, the proliferation, migration, and tube formation abilities of human umbilical vein endothelial cells (HUVECs).

Results: After transfection with miR-24 overexpression plasmid or anti-miR-24, miR-24 was successfully over-expressed or inhibited. Compared with the control group, the HUVEC proliferation and cell number in the miR-24 high expression group was significantly decreased. Moreover, for the miR-24 high expression group, the cell motility was slower, and the migrating cells were significantly decreased by $61.20 \%$, with very few capillaries in the Matrigel assay. Furthermore, the mRNA and protein expression levels of eNOS were decreased by $44.44 \%$ and $47.00 \%$, respectively. Meanwhile, the mRNA and protein levels of Sp1 were significantly decreased by $34.88 \%$ and $68.00 \%$, respectively. In the miR-24 interference group, the above indexes were decreased compared with control group, while significantly increased compared with the miR-24 high expression group, especially concerning the number of branches and the tube length. Moreover, the Sp-1 and eNOS mRNAs were found to be the direct targets of miR-24 by a luciferase reporter system.

Conclusion: Over-expression of miR-24 significantly suppresses cell proliferation, migration, and tube formation ability of HUVECs, via regulating eNOS expression. The transcription factor Sp1, a target of miR-24, might contribute to the eNOS expression regulation and the inhibiting effects on HUVECs.

\section{Background}

In recent years, it has been found that several microRNAs (miRNAs or miRs) are involved in the regulation of proliferation, migration, and morphological changes of vascular endothelial cells, thus modulating the angiogenesis process. However, the abnormal expression of these miRNAs has also been shown to be related to the development of cardiovascular diseases $(1,2)$. Endothelial nitric oxide synthase (eNOS) is an endothelial tissue-specific gene that mediates most of the endogenous nitric oxide (NO) synthesis in the blood vessels. Endogenous NO is not only a regulating factor of the vascular tone, but also participates in modulating the proliferation and migration of endothelial cells, vascular remodeling, and angiogenesis process (3).

$\mathrm{Sp} 1$ is the one of the representative members of the zinc finger protein family, which binds to DNA via three conserved zinc finger structures, plays important regulatory roles in the expression of many genes. Interestingly, the GC box of the eNOS core promoter region contains sites with high affinity for Sp1, and $\mathrm{Sp} 1$ is an essential transcription factor for eNOS. Our previous studies suggest that the regulating effects of miR-24 on the endothelial cell proliferation and its inhibiting effects on eNOS are related to the expression of Sp1 (4). However, whether the inhibiting effects of miR-24 on the expression of eNOS are involved in the regulation of angiogenesis is still unclear.

In this study, the molecular mechanisms underlying the regulation of miR-24 on the expression of eNOS and Sp1 were investigated. Its effects on the proliferation and migration of endothelial cells and the 
luminal formation were also analyzed. Human umbilical vein endothelial cells (HUVECs) were used as in vitro models, and the high expression plasmids of miR-24 and its antisense sequences were constructed. The plasmids were transfected into the HUVECs, and the cell proliferation and migration, as well as the angiogenesis, were evaluated. The expression levels of eNOS and Sp1 were detected.

\section{Results}

\section{Effects of miR-24 on proliferation of HUVECs}

To investigate the effects of miR-24 on the proliferation of HUVECs, the MTT assay was performed. Our results showed that, the cell proliferation was significantly inhibited in the miR-24 high expression group. After 72-h-culture, compared with the control group, the OD value in the miR-24 high expression group was declined by $46.84 \%(0.42 \pm 0.01$ vs. $0.79 \pm 0.03 ; P<0.01)$, while the OD value in the miR-24 interference group $(0.57 \pm 0.02)$ was significantly declined by $27.85 \%(P<0.01)$. The OD value in the miR24 interference group was $35.71 \%$ higher than the miR-24 high expression groups $(P<0.01)$ (Fig. 1). These results suggest that miR-24 might inhibit the proliferation of HUVECs in vitro.

\section{Effects of miR-24 on migration of HUVECs}

To investigate the effects of miR-24 on the migration ability of HUVECs, the Scratch assay and the Transwell chamber assay were performed. Our results from the Scratch assay showed that, at $24 \mathrm{~h}$ after scratching, compared with the control group, the migration rate of HUVECs in the miR-24 high expression group was significantly decreased by $55.56 \%$ ( $0.32 \pm 0.01$ vs. $0.72 \pm 0.01 ; P<0.01)$, while the migration rate in the miR-24 interference group $(0.51 \pm 0.02)$ was declined by $29.17 \%(P<0.01)$. Compared with the miR-24 high expression group, the migration rate in the miR-24 interference group was increased by 59.38\% $(P<0.01)$ (Fig. 2A)

On the other hand, our results from the Transwell chamber assay showed that, compared with the control group, the migrating cells in the miR-24 high expression group were significantly decreased by $61.20 \%$ ( $160.00 \pm 4.24$ vs. $412.40 \pm 5.85 ; P<0.01$ ), while the cell number in the miR-24 interference group (269.00 $\pm 4.00)$ was significantly decreased by $34.77 \%(P<0.01)$. Compared with the miR-24 high expression group, the migrating cell number in the miR-24 interference group was significantly increased by $68.13 \%$ $(P<0.01)$ (Fig. 2B). Taken together, these results suggest that miR-24 could, to some extent, inhibit the migration ability of HUVECs.

\section{Effects of miR-24 on tube formation ability of HUVECs}

The proliferation and migration abilities of HUVECs are closely linked with the tube formation process. In investigate the effects of miR-24 on the tube formation ability of HUVECs, the Matrigel assay was performed. Our results showed that, compared with the control group, the tube number, length, and width were relatively decreased in the miR-24 interference group. However, in the miR-24 high expression group, 
the HUVECs were prone to aggregate, even though no tube-like network structure was formed (Fig. 3). These results suggest that, miR-24 might inhibit the tube formation ability of HUVECs.

\section{Effects of miR-24 on expression levels of eNOS and Sp1 in HUVECS}

To investigate the effects of miR-24 on the expression levels of eNOS and Sp1 in HUVECs, RT-PCR and Western blot analysis were performed. Our results from the RT-PCR showed that, compared with the control group, the mRNA expression level of eNOS in the miR-24 high expression group was significantly declined by $44.44 \%(0.45 \pm 0.03$ vs. $0.81 \pm 0.01 ; P<0.01)$, while the eNOS mRNA level in the miR-24 interference group $(0.65 \pm 0.02)$ was declined by $19.75 \%(P<0.01)$. Compared with the miR-24 high expression group, the eNOS mRNA expression level in the miR-24 interference group was increased by $44.44 \%(P<0.01)$. For the Sp1, compared with the control group, the mRNA expression level of Sp1 in the miR-24 high expression group was significantly declined by $34.88 \%(0.56 \pm 0.02$ vs. $0.86 \pm 0.02 ; P<$ $0.01)$, while the Sp1 mRNA level in the miR-24 interference group $(0.73 \pm 0.02)$ was declined by $15.12 \%$ ( $P$ $<0.01)$. Compared with the miR-24 high expression group, the Sp1 mRNA expression level in the miR-24 interference group was increased by $30.36 \%(P<0.01)$ (Fig. 4).

Similar results were obtained from the Western blot analysis. Our results showed that, compared with the control group, the protein expression level of eNOS in the miR-24 high expression group was significantly declined by $47.00 \%(0.53 \pm 0.01$ vs. $1.00 \pm 0.02 ; P<0.01)$, while the eNOS protein level in the miR-24 interference group $(0.73 \pm 0.02)$ was declined by $27.00 \%(P<0.01)$. Compared with the miR-24 high expression group, the eNOS protein expression level in the miR-24 interference group was increased by $37.74 \%(P<0.01)$. For the Sp1, compared with the control group, the protein expression level of Sp1 in the miR-24 high expression group was significantly down-regulated by $68.00 \%(0.32 \pm 0.02$ vs. $1.00 \pm 0.03 ; P$ $<0.01)$, while the Sp1 protein level in the miR-24 interference group $(0.58 \pm 0.03)$ was declined by $42.00 \%$ $(P<0.01)$. Compared with the miR-24 high expression group, the Sp1 mRNA expression level in the miR24 interference group was increased by $81.25 \%(P<0.01)$ (Fig. 4). Taken together, these results suggest that, miR-24 could significantly down-regulated the expression of eNOS and Sp1 in the HUVECs, on both the mRNA and protein levels.

\section{Discussion}

In present study, our results showed that miR-24 significantly inhibited the expression levels of eNOS and the transcription factor of Sp1 in the HUVECs. Together with miR-24, Sp1 (as an important regulatory factor) participated in the regulation of eNOS expression. Moreover, the regulatory mechanisms may be related to the inhibiting effects of miR-24 on the tube formation ability of HUVECs. Furthermore, our results showed that miR-24 might inhibit the proliferation of HUVECs. These results suggest that miR-24 might regulate the angiogenesis by regulating the endothelial cell proliferation and tube formation. 
Angiogenesis refers to the process concerning the formation of new blood vessels from the original blood vessels, which not only occurs throughout the entire life process, but also play an important role in the pathogenesis of cardiovascular diseases. Recent studies have shown that angiogenesis is closely related to the regulating effects of certain miRNAs. For example, maturation of interfering miRNAs in the endothelial cells would affect the endothelial cell function and angiogenesis ability. Moreover, in the rat models, knock-out of the Dicer gene during gestation might cause abnormal angiogenesis and even embryo death.

MiR-24 belongs to the miR-23-27-24 family, with the highest expression in the heart, especially in the vascular tissues (5). It is noteworthy that 16 miRNAs are significantly down-regulated in the plasma of hypertensive patients, while 14 miRNAs (including miR-24) are significantly up-regulated. Moreover, miR24 is positively correlated with the severity and complications of hypertension. However, although significant progress has been made in investigating the regulatory role of miR-24 in the cardiomyocyte apoptosis during the course of myocardial infarction, and the corresponding signaling pathways and biological effects have been gradually elucidated, study of the promoting effects of miR-24 on angiogenesis via regulating endothelial cells is still in its infancy.

The eNOS is a tissue-specific gene, and its product NO is not only a relaxing factor that regulates the vascular tone, but also plays a crucial role in the endothelial cell proliferation and migration, as well as in the vascular remodeling and angiogenesis (3). However, along with the increasing age or the pathological process, the reduced NO production due to endothelial cell dysfunction would lead to weakened angiogenesis, and the reduced repairing capacity of the damaged vascular endothelium. For example, NO production is reduced in patients with heart failure, with reduced circulating endothelial progenitor cells and declined activity. It has been widely recognized that stimulating endothelial cell migration promotes the repairing of vascular endothelium and the formation of capillaries, which might contribute to the treatment of cardiovascular diseases. At present, stem cell transplantation therapy is a novel and promising treatment option for the ischemic heart disease in clinic (6). Recent in vitro experiments have confirmed that the expression of eNOS is closely related to the migration ability of MSCs (7). Further studies suggest that the zinc finger proteins can promote the differentiating direction of the endothelial progenitor cells into the endothelial cells, via enhancing the expression level of eNOS.

$\mathrm{Sp} 1$ is the one of the representative members of the zinc finger protein family. The GC box in the eNOS core promoter region contains sites with high affinity for $\mathrm{Sp} 1$, and $\mathrm{Sp} 1$ is an essential transcription factor for eNOS. Strikingly, miR-24 could promote the directed differentiation of stem cells and the functions of cardiovascular progenitor cells (CPC). MiR-24 could improve the survival rate of CPC after transplanted into the cardiac MI region (8), which promotes the aggregation of these stem cells onto the vascular wall through the chemotaxis effects, making the blood vessels stable and mature. However, further in-depth studies are still needed to elucidate the underlying mechanism.

\section{Conclusion}


In conclusion, our results showed that miR-24 inhibited the proliferation, migration, and tube formation abilities of HUVECs, by regulating the expression levels of eNOS and Sp1. However, the regulatory effects of miR-24 on angiogenesis, and whether it participates in the differentiation of stem cells into endothelial cells, remain to be further explored in the future.

\section{Methods}

\section{Construction and identification of miR-24 high expression plasmid}

The miR-24 sequence was obtained from the http://www.miRbase.org website, which was 5'UGGCUCAGUUCAGCAGGAACAG-3'. The anti-miRNA-24 was used to down-regulate miR-24 and interfere with its action, and the sequence was complementary to miR-24, i.e., 5'-ACCGAGUCAAGUCGUCCUUGUC3'. The control sequence was as follows: 5'-GUCAUCAGUCGAGCUAGACGAG-3'. First-strand DNA was obtained, as well as the corresponding double-stranded DNA. After amplification through PCR, the in vitro recombination was performed, and the fragments were inserted into the pEGP-miR vectors (Cell Biolabs, San Diego, CA, USA). The following vectors were obtained: the pEGP-miRNA-24, pEGP-anti-miRNA-24, and pEGP-control vectors. These vectors were transformed into competent E.coliDH5a host strains, which were cultured on the ampicillin-resistant plates. The correct monoclonal colonies were picked, and after shaking, the plasmid DNA was obtained and subjected to the DNA sequencing (Sangon Biotech, Shanghai, China).

\section{HUVEC culture and transfection}

HUVECs were provided from Procell, Wuhan, Hubei, China. These cells were cultured with the 1640 medium (Gibco, Mt Waverley, Australia), containing $1 \times 10^{5} \mathrm{U} / \mathrm{L}$ penicillin and $100 \mathrm{mg} / \mathrm{L}$ streptomycin, and $10 \%$ fetal bovine serum (FBS; Gibco), in a $37^{\circ} \mathrm{C}, 5 \% \mathrm{CO} 2$ humidified incubator. For the cell transfection, the extracted plasmid concentrations were measured using a NANO nucleic acid analyzer. Then the plasmid was diluted with serum-free 1640 medium to the concentration of $0.01 \mu \mathrm{g} / \mu \mathrm{L}$, which was mixed with the X-treme GENE HP DNA transfection agent (with the ratio of $1 \mu \mathrm{g}: 3 \mu \mathrm{L}$; Roche Diagnostics, Mannheim, Germany). The normal HUVECs were cultured with the mixture medium for $24 \mathrm{~h}$, which was replaced by the 1640 medium containing $10 \%$ FBS, and the fluorescence was detected. These cells were divided into the following groups: the miR-24 high expression, miR-24 interference (anti-miR24), and blank control groups.

\section{MTT assay}

Proliferation of HUVECs was detected by the MTT assay (Solec Technology Co., Ltd., Beijing, China), according to the previously described method (9). Cells were planted onto the 96 -well plate, at the density of $5 \times 10^{3} /$ well. When $50 \%$ confluence was reached, the cells were cultured with serum-free medium for $24 \mathrm{~h}$. At $24 \mathrm{~h}, 48 \mathrm{~h}$, and $72 \mathrm{~h}$ after transfection, $10 \mu \mathrm{L}$ MTT was added into each well to incubate the cells for further $4 \mathrm{~h}$. Then the medium was discarded, and $100 \mu \mathrm{L}$ DMSO was added into each well. After 
shaking for $15 \mathrm{~s}$, the absorbance at $570 \mathrm{~nm}\left(\mathrm{OD}_{570 \mathrm{~nm}}\right)$ was detected on a fluorescence detector. Experiments were performed in triplicates.

\section{Scratch assay and Transwell chamber assay}

Migration abilities of HUVECs were detected by the Scratch assay and Transwell chamber assay. For the Scratch assay (10), the cells were planted onto the 6-well plate, at the density of $4 \times 10^{5} /$ well. After adherence, a short line was marked on the bottom of the plate with the pipette tip. Then the cells were washed with PBS ( $\mathrm{pH} 7.4$ ), and then cultured with serum-free 1640 medium. At $0 \mathrm{~h}$ and $24 \mathrm{~h}$ after this, the migration status was observed, and the short line width was measured. The migration ratio was calculated as follows: Migration ratio $=($ line width at $0 \mathrm{~h}-$ line width at $24 \mathrm{~h}$ ) $/$ line width at $0 \mathrm{~h}$.

On the other hand, the migration ability of HUVECs was also detected by the Transwell chamber assay (3). The cells were planted on the upper chamber in the Transwell plate, at the density of $1 \times 10^{4} /$ well, and cultured with serum-free 1640 medium. The lower chamber was added with $500 \mu \mathrm{L}$ medium containing serum. After $12 \mathrm{~h}$, the upper chamber was removed. The cells were carefully wiped off with a cotton swab, and fixed with $4 \%$ paraformaldehyde for 15 min. The upper chamber was washed with PBS, and stained with crystal violet at room temperature for $1 \mathrm{~h}$. The cells in the lower chamber were observed with the inverted microscope. The five fields were randomly selected, and the cells were counted.

\section{Matrigel assay}

Tube formation capacity of HUVECs was examined by the Matrigel assay (Corning, Corning, NY, USA) (3). The 96 -well plates were pre-coated with Matrigel $(20 \mu \mathrm{L}$ each well) on ice. Then the plated was placed in the $37^{\circ} \mathrm{C}, 5 \% \mathrm{CO}_{2}$ incubator for $1 \mathrm{~h}$. The cells were seeded onto the Matrigel-coated plates, at the density of $1 \times 10^{4} /$ well, and incubated for $12 \mathrm{~h}$. Then five fields were randomly selected, and the small tubes were observed under microscope.

\section{RT-PCR}

Total RNA was extracted with TRIzol. The first-strand DNA was synthesized with the following system: 4 $\mu \mathrm{L} 5 \times$ reaction buffer, $1 \mu \mathrm{L}^{\text {RiboLock }^{\text {TM }}}$ Ribonuclease Inhibitor $(20 \mathrm{U} / \mu \mathrm{L}), 2 \mu \mathrm{L} 10 \mathrm{mmol} / \mathrm{L}$ dNTP Mix, at $37^{\circ} \mathrm{C}$ for $5 \mathrm{~min}$, followed by adding $1 \mu \mathrm{L}$ reverse transcriptase, at $42^{\circ} \mathrm{C}$ for $1 \mathrm{~h}$, and at $70{ }^{\circ} \mathrm{C}$ for $10 \mathrm{~min}$. RT-PCR was performed with the PCR Kit from Tiangen Biotech, Beijing, China. The primer sequences were as follows: eNOS, forward 5'-AGGAACCTGTGTGACCCTCA-3' and reverse 5'-CGAGGTGGTCCGGGTATCC3'; Sp1, forward 5'-AGGTGCACCAGCTTCCAGGCCTG-3' and reverse 5'-CCAGGTCCATGAAGGCCAAGTTG-3'; and $\beta$-actin, forward 5'-CTGGAACGGTGAAGGTGACA-3' and reverse 5'-AAGGGACTTCCTGTAACAATGCA$3^{\prime}$. The PCR conditions were as follows: $94^{\circ} \mathrm{C}$ for $5 \mathrm{~min} ; 94^{\circ} \mathrm{C}$ for $30 \mathrm{~s}, 56^{\circ} \mathrm{C}$ for $1 \mathrm{~min}, 72{ }^{\circ} \mathrm{C}$ for $1 \mathrm{~min}$, for totally 30 cycles; followed by $72{ }^{\circ} \mathrm{C}$ for $5 \mathrm{~min}$. Totally $5 \mu \mathrm{L}$ PCR products were subjected to the $1.5 \%$ agarose gel electrophoresis analysis.

\section{Western blot analysis}


Cell protein was lysed with lysis. The protein concentration was determined, and $30 \mu \mathrm{g}$ protein was subjected to $8 \%$ SDS-PAGE, which was then electronically transferred onto the PVDF membrane. After blocking with non-fat milk for $1 \mathrm{~h}$, the membrane was incubated with rabbit anti-human anti-eNOS primary polyclonal antibody (1:1000 dilution; Abcam, Cambridge, MA, UK) and rabbit anti-human anti-Sp1 primary polyclonal antibody (1:1000 dilution; Abcam), respectively, at $4{ }^{\circ} \mathrm{C}$ overnight. After washing with TBST $(0.14 \mathrm{~mol} / \mathrm{L} \mathrm{NaCl}, 2.7 \mathrm{mmol} / \mathrm{L} \mathrm{KCl}, 24.8 \mathrm{mmol} / \mathrm{L}$ Trise base, and 1\% Tween; $\mathrm{pH}=7.4)$. Then the membrane was incubated by the horseradish peroxidase-conjugated goat anti-rabbit secondary antibody (1:2000 dilution; Santa Cruz, Santa Cruz, CA, USA), at room temperature for $1 \mathrm{~h}$. The protein bands were scanned and analyzed by the Odyssey infrared fluorescence imaging system (Li-Cor Inc., Lincoln, NE, USA).

\section{Statistical analysis}

Data were expressed as mean \pm SD. SPSS 16.0 software was used for statistical analysis. One-way ANOVA was performed for the group comparison, with the LSD-t and SNK-q tests. $P<0.05$ was considered statistically significant.

\section{Abbreviations}

CPC

cardiovascular progenitor cells

eNOS

Endothelial nitric oxide synthase

HUVECS

Human umbilical vein endothelial cells

NO

nitric oxide

\section{Declarations}

\section{Ethics approval and consent to participate}

Not applicable.

\section{Consent for publication}

Not applicable.

\section{Availability of data and materials}

The data that support the findings of this study are available on request from the corresponding author.

\section{Competing interests}


The authors declare that they have no competing interests.

\section{Funding}

This work was supported by the National Natural Science Foundation of China (81373403), and the Guangxi Postgraduate Research Innovation Project (YCSZ2015119). The funding bodies played no role in the design of the study and collection, analysis, and interpretation of data and in writing the manuscript.

\section{Authors' contributions}

WC performed the experiments, acquired data and wrote manuscript. XL contributed reagents, materials and analysis tools. NG performed the experiments. YQ analyzed the data. ZL, DL searched literatures and revised manuscript. HO designed the research, collected funds and wrote manuscript. All authors read and approved the final manuscript.

\section{Acknowledgements}

Not applicable.

\section{References}

1. Luo XY, Zhu XQ, Li Y, Wang XB, Yin W, Ge YS, et al. MicroRNA-150 restores endothelial cell function and attenuates vascular remodeling by targeting PTX 3 through the NF-kappaB signaling pathway in mice with acute coronary syndrome. Cell Biol Int. 2018;42(9):1170-81.

2. Zhao Y, Yan M, Chen C, Gong W, Yin Z, Li H, et al. MiR-124 aggravates failing hearts by suppressing CD151-facilitated angiogenesis in heart. Oncotarget. 2018;9(18):14382-96.

3. Janaszak-Jasiecka A, Siekierzycka A, Bartoszewska S, Serocki M, Dobrucki LW, Collawn JF, et al. eNOS expression and NO release during hypoxia is inhibited by miR-200b in human endothelial cells. Angiogenesis. 2018;21(4):711-24.

4. Zhang W, Yan L, Li Y, Chen W, Hu N, Wang H, et al. Roles of miRNA-24 in regulating endothelial nitric oxide synthase expression and vascular endothelial cell proliferation. Mol Cell Biochem. 2015;405(1-2):281-9.

5. Zhou Q, Gallagher R, Ufret-Vincenty R, Li X, Olson EN, Wang S. Regulation of angiogenesis and choroidal neovascularization by members of microRNA-23 $27 \sim 24$ clusters. Proceedings of the National Academy of Sciences of the United States of America. Proc Natl Acad Sci U S A. 2011;108(20):8287-92.

6. Premer C, Blum A, Bellio MA, Schulman IH, Hurwitz BE, Parker M, et al. Allogeneic Mesenchymal Stem Cells Restore Endothelial Function in Heart Failure by Stimulating Endothelial Progenitor Cells. EBioMedicine. 2015;2(5):467-75.

7. Lin YL, Yet SF, Hsu YT, Wang GJ, Hung SC. Mesenchymal Stem Cells Ameliorate Atherosclerotic Lesions via Restoring Endothelial Function. Stem Cells Transl Med. 2015;4(1):44-55. 
8. Hu S, Huang M, Nguyen PK, Gong Y, Li Z, Jia F, et al. Novel microRNA prosurvival cocktail for improving engraftment and function of cardiac progenitor cell transplantation. Circulation. 2011;124(11 Suppl):27-34.

9. Hung HS, Chang $\mathrm{CH}$, Chang CJ, Tang CM, Kao WC, Lin SZ, et al. In vitro study of a novel nanogoldcollagen composite to enhance the mesenchymal stem cell behavior for vascular regeneration. PloS one. 2014;9(8):e104019.

10. Pafumi I, Favia A, Gambara G, Papacci F, Ziparo E, Palombi F, et al. Regulation of Angiogenic Functions by Angiopoietins through Calcium-Dependent Signaling Pathways. Biomed Res Int. 2015;2015:965271.

\section{Figures}

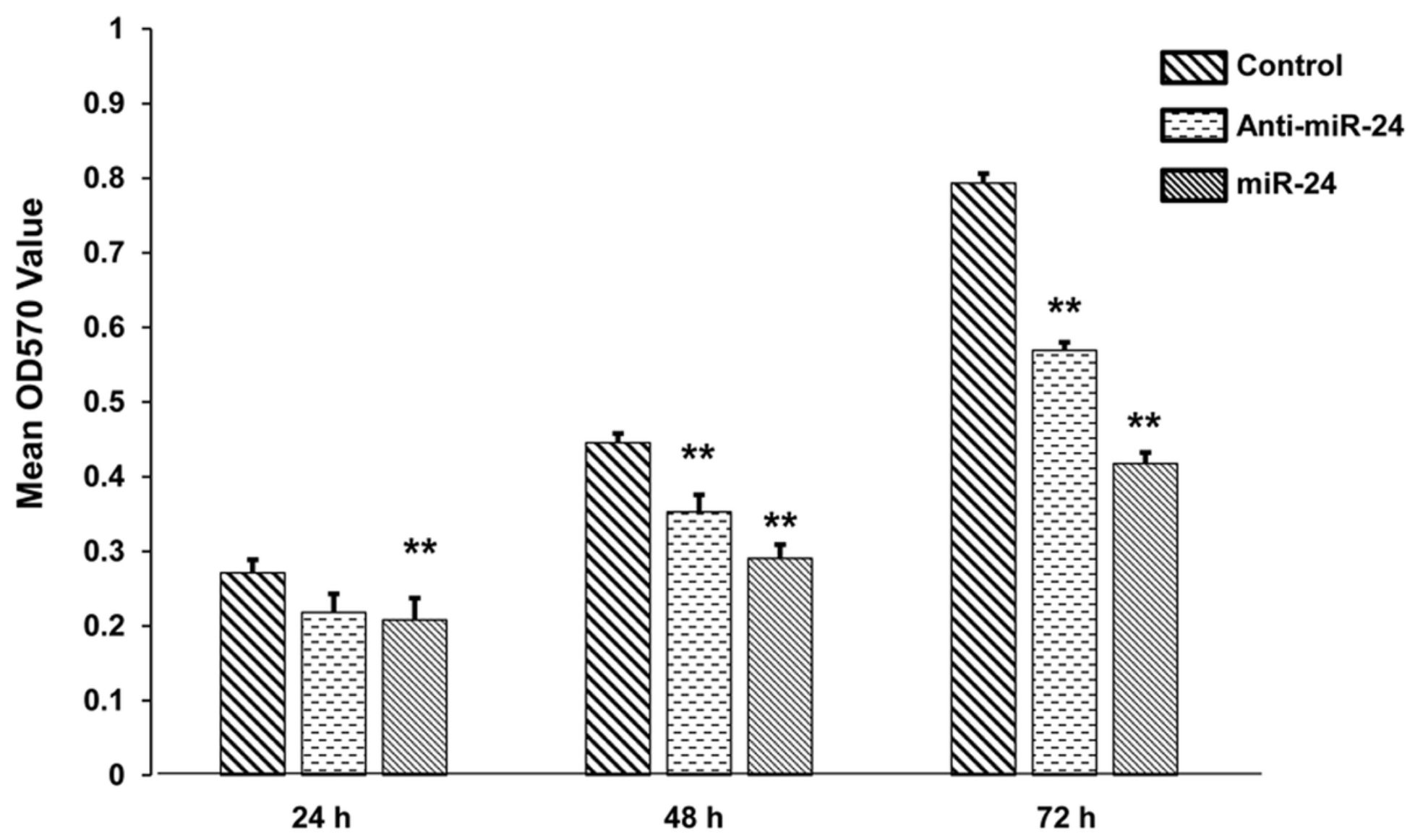

Figure 1

Effects of miR-24 on proliferation of HUVECs. HUVECs were transfected with the control, anti-miR-24, and miR-24 plasmids, respectively. Cell proliferation was measured by the MTT assay at $24 \mathrm{~h}, 48 \mathrm{~h}$, and $72 \mathrm{~h}$. Compared with the control group, $* * \mathrm{P}<0.01$. 
A

Control

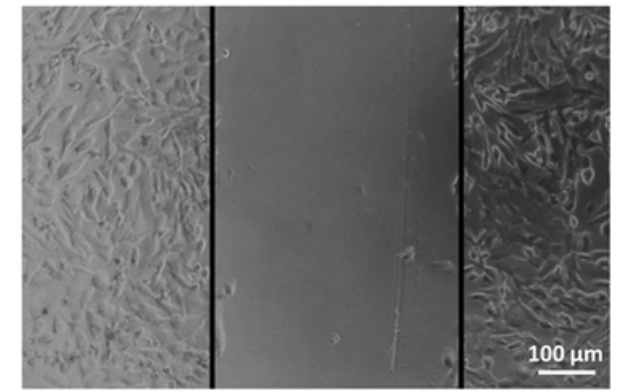

O h

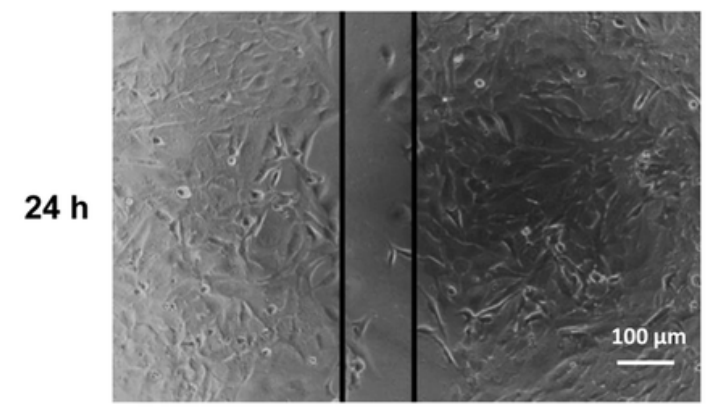

B

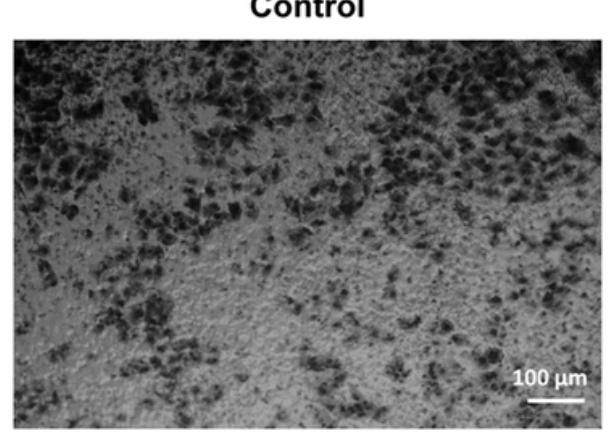

Anti-miR-24
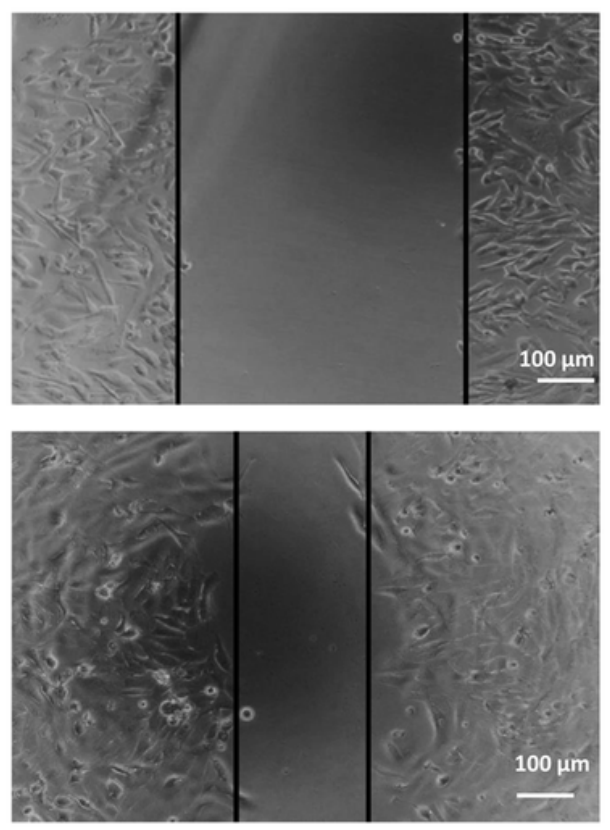

Anti-miR-24

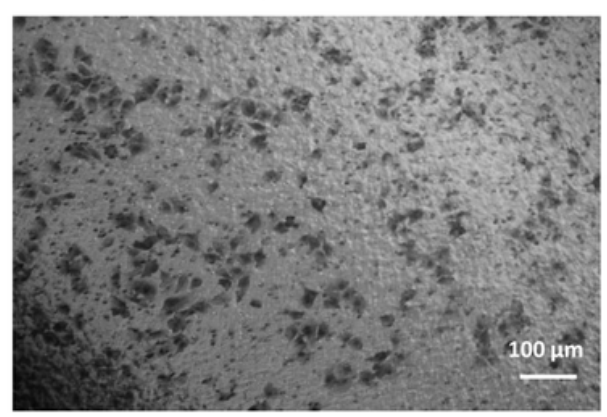

MiR-24
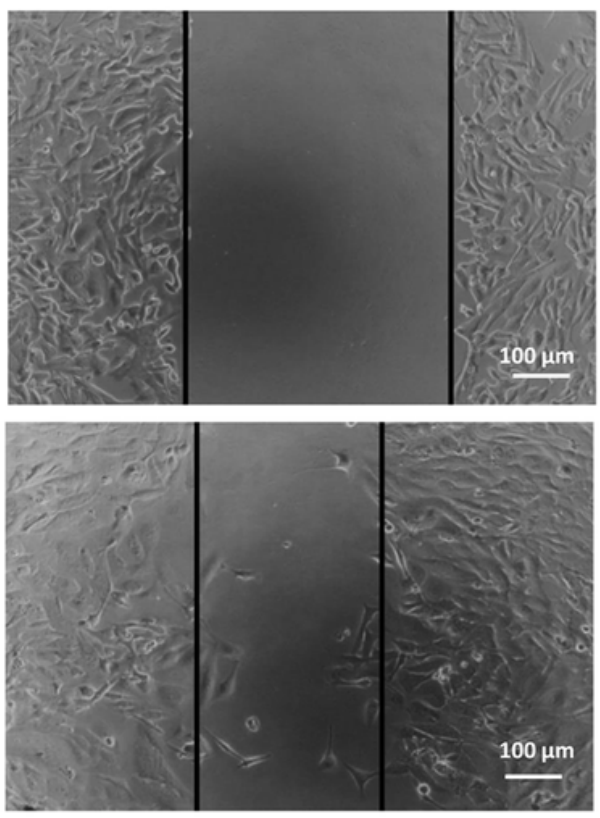

MiR-24

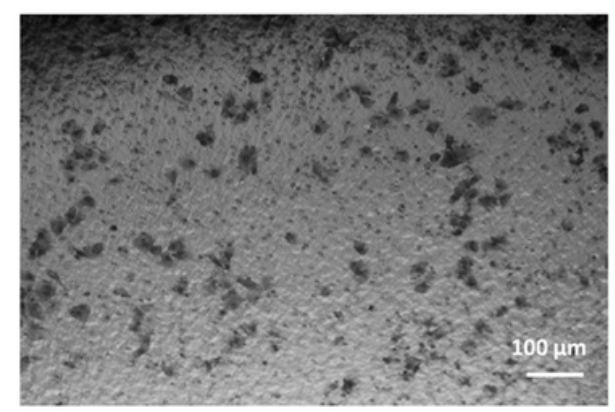

Figure 2

Effects of miR-24 on the migration ability of HUVECs. HUVECs were transfected with the control, anti-miR24 , and miR-24 plasmids, respectively. The cell migration abilities were assessed with the Scratch assay (A) and Transwell chamber assay (B). (A) Representative images showing the line width for each group in the Scratch assay. (B) The cells in the lower chamber in the Transwell chamber assay. Scale bar: $100 \mu \mathrm{m}$.

Control

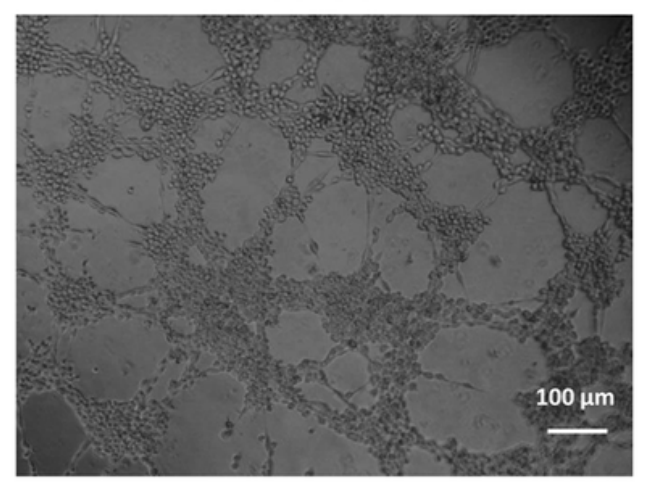

Anti-miR-24

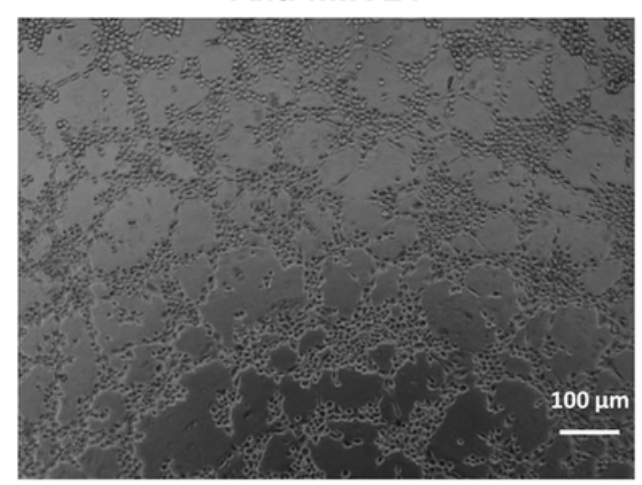

\section{MiR-24}

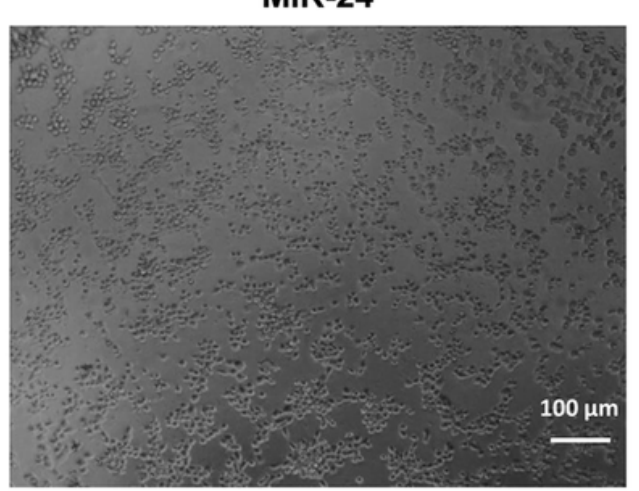

\section{Figure 3}


Effects of miR-24 on the tube formation ability of HUVECs. HUVECs were transfected with the control, anti-miR-24, and miR-24 plasmids, respectively. The Matrigel assay was performed to assess the tube formation ability of HUVECs. Scale bar: $100 \mu \mathrm{m}$.

A

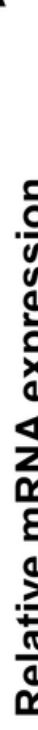

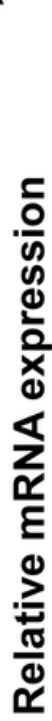
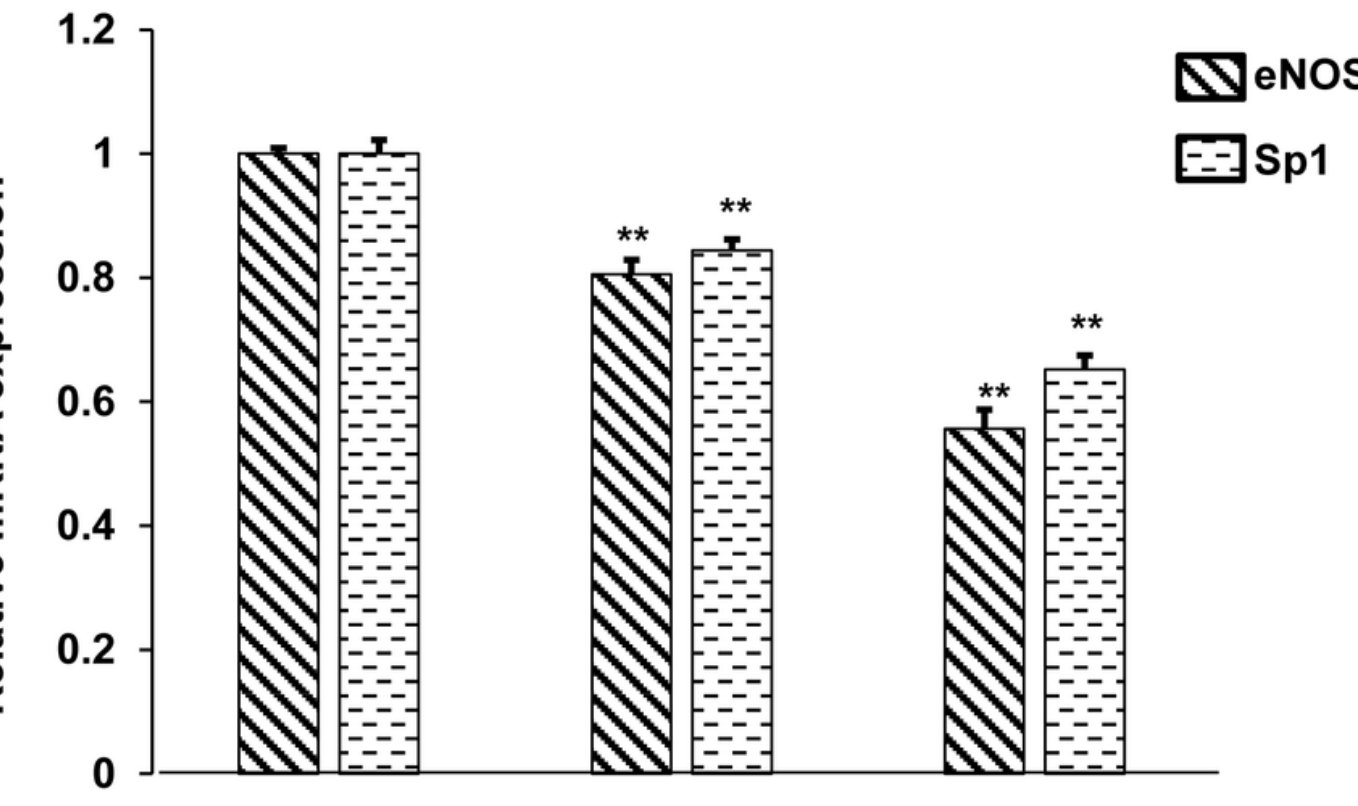

Control

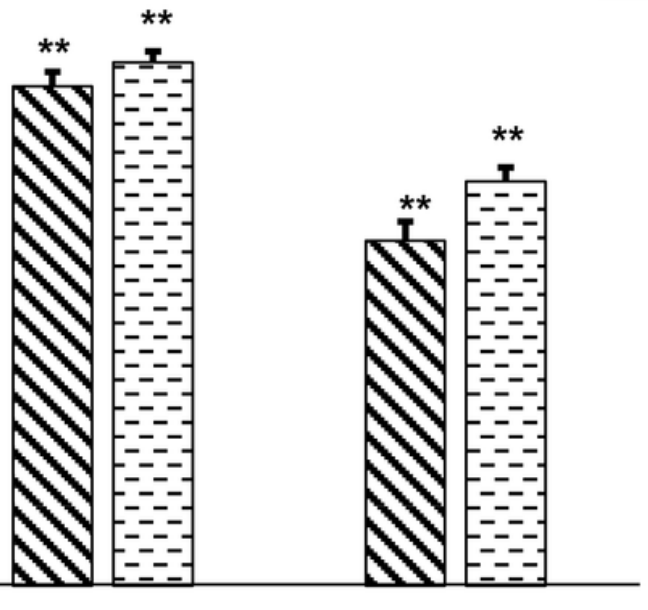

Anti-miR-24

miR-24

B

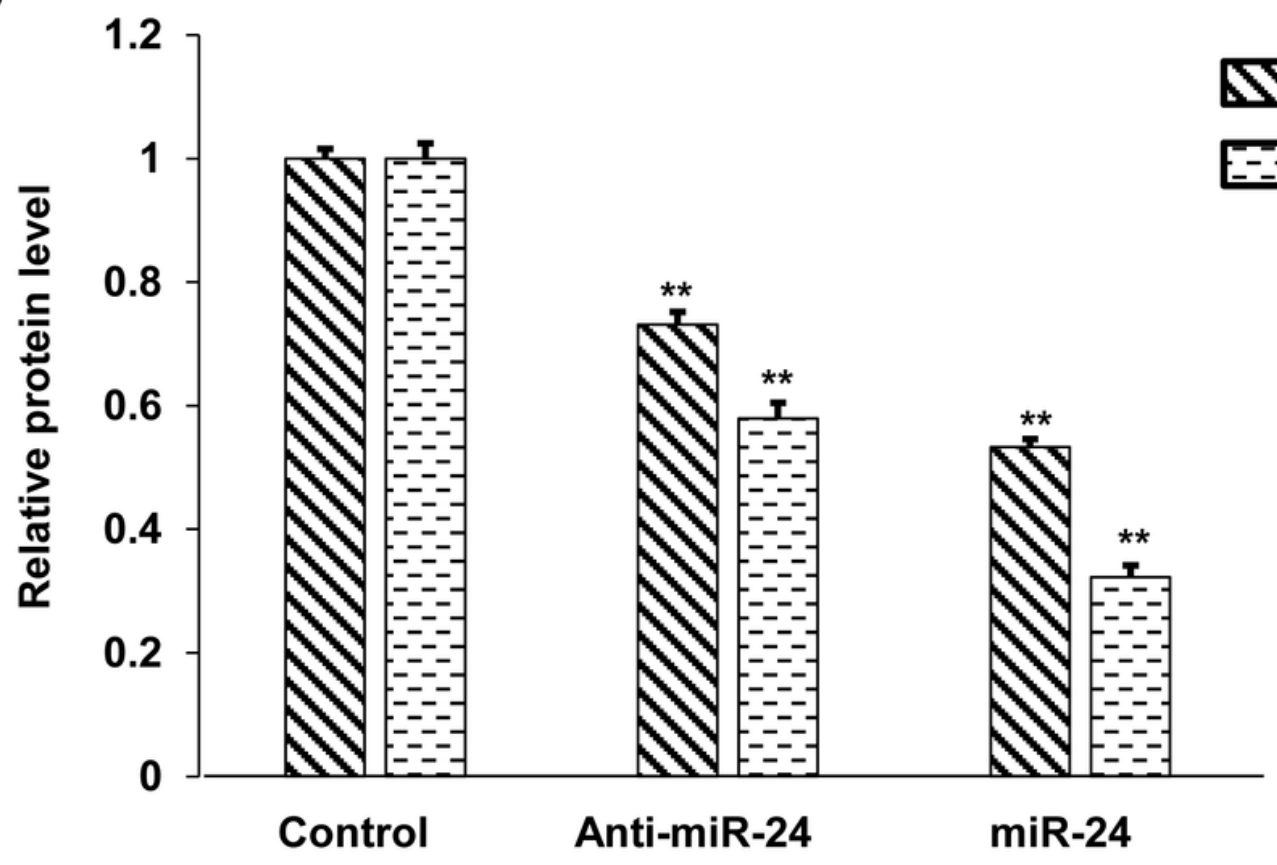

WeNOS

E-Gsp1

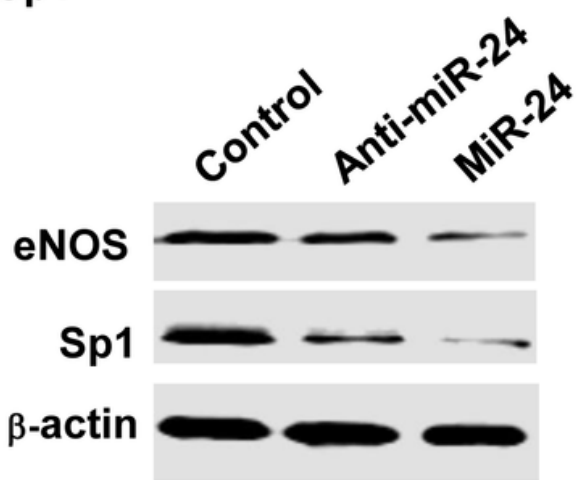

Figure 4

Effects of miR-24 on the expression levels of eNOS and Sp1 in HUVECs. HUVECs were transfected with the control, anti-miR-24, and miR-24 plasmids, respectively. The mRNA and protein expression levels of eNOS and Sp1 in the HUVECs were detected with the quantitative real-time PCR (A) and Western blot analysis (B). Compared with the control group, ${ }^{\star *} \mathrm{P}<0.01$. 


\section{Supplementary Files}

This is a list of supplementary files associated with this preprint. Click to download.

- originalimages.jpg 